\title{
La Obligación del Congreso de Jalisco para Legislar en Materia de Matrimonio Igualitario y Adopción Homoparental
}

\section{The Obligation of the Congress of Jalisco to Legislate on Equal Marriage and Gay Adoption}

AUTOR: Mtra. Erika Crystal Zavala López

SUMARIO: I. Introducción II. Marco constitucional; III. Marco internacional y su aplicación en el estado; IV. Sentencia de la Corte Interamericana de los derechos humanos; V. Criterios Jurisprudenciales de la Suprema Corte de Justicia de la Nación; VI. Mecanismos de interpretación utilizados por la Suprema Corte de Justicia de la Nación; VII. Sentencia del Tribunal de Distrito en Materia Civil del Estado de Jalisco; VIII. Conclusiones.

Resumen: Los criterios jurisprudenciales realizados en junio del 2015 por la Suprema Corte de Justicia de la Nación entorno a la inconstitucionalidad de los ordenamientos que enumeran al matrimonio como exclusivo de las parejas heterosexuales, marca precedente para formular la directriz que se debe seguir en este tema. Aunado a ello se establece la obligación que la constitución mexicana estipula en su artículo primero para que las autoridades en el marco de su competencia protejan y garanticen el cumplimiento de los derechos humanos, escenario que pone de manifiesto la obligación del legislativo para actualizar el ordenamiento civil.

Palabras Clave: Matrimonio igualitario, adopción homoparental, derechos humanos.
Abstract: The legal criteria made in June 2015 by the Supreme Court of Justice around the unconstitutionality of laws that list marriage as exclusively for heterosexual couples, marks a binding precedent to formulate the guideline to be followed in this matter. Added to this obligation, it is established that the Mexican constitution stipulates in its first article that the authorities in the framework of its competence to protect and enforce human rights, a scenario that reflects the obligation to update the civil law.

Key Words: Equal Marriage, Homoparental adoption, Human Rights.

\section{Introducción}

Los temas jurídicos y sociológicos que involucran a la homosexualidad, siempre tienen múltiples controversias de carácter moral; cualquiera que sea el aspecto social de la vida cotidiana del ser humano, primordialmente los cuestionamientos sobre los derechos humanos -inalienables e irrenunciables-, siempre han chocado con su concreta aplicación 
cuando el tema de la moralidad les salpica, sobresaliendo los derechos para votar y ser votados, hasta temas muy contemporáneos como el matrimonio igualitario, la homoparentalidad o los derechos de adopción.

El pasado 04 de julio de 2014, la Suprema Corte de Justicia de la Nación (SCJN) publicó en el Semanario Oficial de la Federación, dos tesis aisladas en las que se pronuncian ante la inconstitucionalidad de los ordenamientos que limitan el derecho al matrimonio para "un solo hombre y una mujer"1, y se afirmó que no existe razón de índole constitucional para no reconocer el matrimonio entre dos personas del mismo sexo ${ }^{2}$.

Con lo manifestado por los ministros de la SCJN, se marca precedente y un criterio a seguir por parte de jueces y tribunales a fin de conceder el matrimonio entre personas del mismo sexo en las entidades en las cuales no se encuentra regulado. Aunado a este pronunciamiento se suma el imperativo establecido por la constitución para que las legislaciones de las entidades federativas sean reformadas.

Empero a lo anterior, la situación que vive Jalisco no es un caso aislado en el País, hasta el momento, tan sólo el Distrito Federal, Quintana Roo y Coahuila han reformado su legislación para integrar el matrimonio de forma igualitaria; aún a pesar de los pronunciamientos dados por la Suprema Corte las demás entidades han sido omisas ante su obligación de protección a los derechos humanos, lo que expone el profundo marco de desigualdad y violación a los derechos en el que se encuentra México.

Por otra parte, reafirmando las tesis antes señaladas, el 26 de enero del año en curso la SCJN resolvió la acción de inconstitucionalidad promovida por la Comisión Nacional de los Derechos Humanos (CNDH), sobre los artículos 258, 260 y 267 bis, mismos sobre los cuales versa el matrimonio en el estado de Jalisco, de esta forma los ministros resolvieron por unanimidad la inconstitucionalidad de dichos artículos, imponiendo además la obligación al estado (entre ellos al

\footnotetext{
${ }^{1}$ Tesis aislada (constitucional); 1a. CCLIX/2014 (10a), publicada el 04 de julio de 2014, No.2006876. De la primera sala; con título: Matrimonio. La ley que, por un lado, considera que la finalidad de aquél es la procreación y/o que lo define como el que se celebra entre un hombre y una mujer, es inconstitucional. ${ }^{2}$ Tesis aislada (constitucional) 1a . CCLX/2014 (10a), publicada el 04 de julio de 2014, No. 2006875. De la primera sala; con título: Matrimonio. Entre personas del mismo sexo. No existe razón de índole constitucional para no reconocerlo.
} 
Congreso Jalisciense) de eliminar que un matrimonio debe de llevarse a cabo entre un hombre y mujer.

El pronunciamiento dado por la Suprema Corte ha provocado que diversos grupos sociales y partidistas manifiesten su inconformidad creando así un movimiento social denominado "Jalisco es uno por los niños", el cual tiene la consigna de impedir se lleve a cabo las reformas al Código Civil estatal y a la Constitución de la Entidad a efecto de otorgar el derecho al matrimonio a las personas del mismo sexo; sus argumentos se han escudado en la protección de los derechos de los niños a que tengan una familia tradicional y no sean adoptados por personas del mismo sexo. Aunando a lo anterior, estos grupos han salido a las calles en marchas de protesta y levantando la amenaza que de realizarse las reformas señaladas "castigaran electoralmente" a los diputados que se pronuncien a favor.

La reticencia de los legisladores del Congreso estatal hasta este momento para legislar en materia de matrimonio igualitario se ha hecho palpable a causa de las presiones ejercidas por diversos sectores sociales conservadores, entre los que se encuentra la iglesia católica y el Partido de Acción Nacional (PAN), bajo el temor de abrir con ello el derecho de adopción a los homosexuales.

No obstante,más allá de las creencias y opiniones personales que se puedan expresar por parte de estos sectores y grupos sociales, existe la obligatoriedad por parte del legislativo para reformar los artículos 258, 260, 267 bis y 539 a favor del matrimonio igualitario y la adopción homoparental; esta obligación se fundamenta en lo siguiente.

\section{Marco constitucional}

La reforma al artículo $1^{\circ}$ Constitucional, del 10 de junio de 2011, ha logrado cambiar el paradigma jurídico mexicano, estableciendo lo siguiente:

"Artículo $1^{\circ}$. En los Estados Unidos Mexicanos todas las personas gozarán de los derechos humanos reconocidos en esta Constitución y en los tratados internacionales de los que el Estado 
Mexicano sea parte, así como de las garantías para su protección ${ }^{3}$, cuyo ejercicio no podrá restringirse ni suspenderse, salvo en los casos y bajo las condiciones que esta Constitución establece.

Las normas relativas a los derechos humanos se interpretarán de conformidad con esta Constitución y con los tratados internacionales de la materia favoreciendo en todo tiempo a las personas la protección más amplia ${ }^{4}$.

Todas las autoridades, en el ámbito de sus competencias, tienen la obligación de promover, respetar, proteger y garantizar los derechos humanos de conformidad con los principios de universalidad, interdependencia, indivisibilidad y progresividad. En consecuencia, el Estado deberá prevenir, investigar, sancionar y reparar las violaciones a los derechos humanos, en los términos que establezca la ley.

Está prohibida la esclavitud en los Estados Unidos Mexicanos. Los esclavos del extranjero que entren al territorio nacional alcanzarán por este solo hecho, su libertad y la protección de las leyes.

Queda prohibida toda discriminación motivada por origen étnico o nacional, el género, la edad, las discapacidades, la condición social, las condiciones de salud, religión, las opiniones, las preferencias sexuales, el estado civil o cualquier otra que atente contra la dignidad humana y tenga por objeto anular o menoscabar los derechos y libertades de las personas." (Diario Oficial de la Federación , 2011)

Dentro de este artículo se establecen diversos aspectos a resaltar; por una parte la protección de todas las personas en el marco de los derechos humanos enmarcados no sólo en la Constitución, sino también dentro de los Tratos Internacionales de los que México forma parte, fincando la mayor protección en base al principiopro homineo principio pro persona; en segundo lugar la obligación de parte de todas las autoridades para en el ámbito de sus competencias se protejan y garanticen los derechos humanos.

Con sustento en estos preceptos se constituye la obligación de los legisladores del Congreso del estado de Jalisco para reformar el

${ }^{3}$ El subrayado se ha agregado por la autora del presente artículo.

${ }^{4}$ Ibidem 6. 
ordenamiento civil de la entidad a fin de proteger y garantizar que no se sigan violentando los derechos humanos de igualdad, no discriminación y derecho a la familia mismos que otorga nuestra Carta Magna en los artículos $1^{\circ}$ y $4^{\circ}$.

\section{Marco legal internacional y su aplicación en el estado}

En lo que se refiere a la legalidad del matrimonio homosexual, aproximadamente una veintena de países a nivel mundial lo contemplan, entre los que se encuentran: Holanda, Bélgica, Canadá, España, Sudáfrica, Noruega, Suecia, Portugal, Islandia, Argentina, Dinamarca, Nueva Zelanda, Uruguay, Francia, Luxemburgo, Brasil, Irlanda, Estados Unidos y Grecia.

México por su parte ha firmado diversos tratados y convenios internacionales en materia de derechos humanos, obligándolo como País parte a que sus acciones y sus leyes sean acordes a lo establecido en estos documentos internacionales, sin embargo, así mismo los tribunales del País están facultados en base al artículo 103 constitucional a interpretar la ley o a realizar acciones que en base al marco constitucional den aplicación a estos tratados internacionales respecto a cualquier controversia en la que se estén violentando derechos humanos.

En base a la práctica anterior ha surgido una doctrina llamada margen de apreciación de los derechos humanos, la cual es definida por Francisco R. Barbosa como:

"el campo de acción e interpretación de los derechos fundamentales, dejando a las autoridades soberanas del Estado y a los jueces internacionales." (Barbosa Delgado, Acosta Alvarado, \& Nuñez Poblete, 2012)

Dicha doctrina ha sido utilizada por el Tribunal Europeo de Derechos Humanos, y su aplicación dentro del ámbito nacionalse encuentra facultado por la constitución, tratados y criterios internacionales en los cuales el estado mexicano se debe de basar para interpretar en concordancia con lo marcado por la Carta Magnaante controversias, y así dar resolución a las violaciones que se comentan en materia de derechos humanos 
Realizando un margen de apreciación de los derechos humanos en el caso concreto de la desigualdad ante el derecho a contraer matrimonio y adoptar de las personas del mismo sexo, la interpretación por parte de jueces y autoridades del Estado llevaría al estudio de la aplicación de los siguientes documentos de orden internacional que están en contra de la discriminación:

- Declaración Universal de los Derechos Humanos de la Organización de las Naciones Unidas (ONU), 1948, artículo 1: "Todos los seres humanos nacen libres e iguales en dignidad y derechos y, dotados como están de razón y conciencia, deben comportarse fraternalmente los unos con los otros"(Naciones unidas)

- La Carta de la Organización de Estados Americanos de 1948, la cual señala en su artículo 3.1, como principio básico que "Los Estados Americanos proclaman los derechos fundamentales de la persona humana sin hacer distinción de raza, nacionalidad, credo o sexo"(Organización de los Estados Americanos)

- Convención Americana sobre los Derechos Humanos, San José, Costa Rica, en su artículo 1.1 señala: "Los Estados Partes en esta Convención se comprometen a respetar los derechos y libertades reconocidos en ella y a garantizar su libre y pleno ejercicio a toda persona que esté sujeta a su jurisdicción, sin discriminación alguna por motivos de raza, color, sexo, idioma, religión, opiniones políticas o de cualquier otra índole, origen nacional o social, posición económica, nacimiento o cualquier otra condición social. (Organización de los Estados Americanos)

- Protocolo adicional a la Conveción Americana sobre Derechos Humanos en materia de Derechos Económicos, sociales, y culturales "Protocolo de San Salvador", en su artículo 3: "Los Estados partes en el presente Protocolo se comprometen a garantizar el ejercicio de los derechos que en él se enuncian, sin discriminación alguna por motivos de raza, color, sexo, idioma, religión, opiniones políticas o de cualquier otra índole, origen nacional o social, posición económica, nacimiento o cualquier otra condición social." (Organización de los Estados Americanos)

- Carta Democrática Interamericana, en su artículo 9, establece: "La eliminación de toda forma de discriminación, especialmente la discriminación de género, étnica y racial, y de las diversas formas de intolerancia, así como la promoción y protección de los derechos 
humanos de los pueblos indígenas y los migrantes y el respeto a la diversidad étnica, cultural, reliogiosa en las Américas, contribuyen al fortalecimiento de la democracia y la participación ciuidadana. (Organización de los Estados Americanos)

En lo que respecta al derecho a la familia per se como un elemento natural, básico o fundamental del orden social, tenemos:

- La Declaración Universal de Derechos Humanos (1948) que reconoce en el artículo 16, apartado 3, a la familia como: "el elemento natural y fundamental de la sociedad y del Estado", señalando de igual forma que los hombres y las mujeres, a partir de la edad núbil, tienen derecho sin restricción alguna por motivos de raza, nacionalidad o religión, a casarse y fundar una familia. (Asamblea General Organización de las Naciones Unidas, 1948)

- La Declaración Americana de los Derecho y Deberes del Hombre (1948) afirmando en el artículo sexto que: "toda persona tiene derecho a constituir familia, elemento fundamental de la sociedad, y a recibir protección para ella”.(Comisón Interamericana de los Derecho Humanos, 1948)

- El Pacto Internacional de Derechos Económicos, Sociales y Culturales de las Naciones Unidas (1966), establece en el artículo décimo a la familia como "el elemento natural y fundamental de la sociedad la cual debe de tener la más amplia protección y asistencia posible, especialmente para su constitución y mientras sea responsable del cuidado y la educación de los hijos a su cargo". (Organización de las Naciones Unidas, 1966).

- Así mismo la Organización de las Naciones Unidas, realizó el Pacto Internacional de los Derecho Civiles y Políticos, estableciendo en el artículo 23, de la misma forma que en el Pacto anterior, que la familia es: "el elemento natural y fundamental de la sociedad y tiene derecho a la protección de la sociedad y del Estado". (Organización de las Naciones Unidas, 1966)

- Convención Americana de Derechos Humanos, Pacto de San José de Costa Rica (1969), reconoce en su artículo 17 a la familia como un elemento natural y fundamental de la sociedad y debe ser

\footnotetext{
${ }^{5}$ Se subraya por parte de la autora de este artículo los elementos y características que la propia Declaración Universal de los Derechos Humanos adhiere al concepto de la familia a fin de resaltar la importancia y valor concedido por parte de Órganos Internacionales.
} 
protegida por la sociedad y el Estado". ${ }^{6}$ (Convención Americana de los Derechos Humanos, 1969)

Así mismo además de la igualdad, la familia toma vital importancia para los aspectos jurídicos y sociales desde la concepción de que es el elemento básico y originario de la sociedad. Ante los órganos internaciones, su protección y tutela por parte del Estado es incuestionable, y debe ser primordial; sin embargo, la conceptualización de la familia varía según la perspectiva y el enfoque de estudio, cultura o sociedad en que se trate, por ello, la Organización de las Naciones Unidas en el documento de Observaciones Generales No. 19, Comentarios Generales adoptados por el Comité de los Derecho Humanos, artículo 23- La familia, en su párrafo segundo, $39^{\circ}$ período de sesión, de 1990, el Comité de Derecho Humanos demanda el reconocimiento de los diversos modelos de familia existentes en un estado, estableciendo:

"El Comité observa que el concepto de familia puede diferir en algunos aspectos de un Estado a otro, y aun entre regiones dentro de un mismo Estado, de manera que no es posible dar una definición uniforme del concepto. Sin embargo, el Comité destaca que, cuando la legislación y la práctica de un Estado consideren a un grupo de personas como una familia, éste debe ser objeto de la protección prevista en el artículo 23. Por consiguiente, en sus informes, los Estados Partes deberían exponer la interpretación o la definición que se da del concepto de familia y de su alcance en sus sociedades y en sus ordenamientos jurídicos. Cuando existieran diversos conceptos de familia dentro de un Estado, "nuclear" y "extendida", debería precisarse la existencia de esos diversos conceptos de familia, con indicación del grado de protección de una y otra. En vista de la existencia de diversos tipos de familia, como las de parejas que no han contraído matrimonio y sus hijos y las familias monoparentales, los Estados Partes deberían también indicar en qué medida la legislación y las prácticas nacionales reconocen y protegen a esos tipos de familia y a sus miembros ${ }^{7}$."

\footnotetext{
${ }^{6}$ Para una mayor referencia sobrelostratadosinternacionales existentes en materia de derechos humanos (no solo protección de la familia) que han sido firmados por México, se recomienda ver el libro Compilación de instrumentos internacionales de derechos humanos firmados y ratificados por México 1921-2003, es sus volúmenes I y II, realizado en México por la Comisión Nacional de los Derechos Humanos, en 2004. 7 Se resalta en negritas por parte de la autora de esta artículo los elementos y características que la propia Declaración Universal de los Derechos Humanos adhiere al concepto de la familia a fin de resaltar la importancia y valor concedido por parte de Órganos Internacionales
} 


\section{Sentencia de la Corte Interamericana de Derechos Humanos}

Por su parte la Corte Interamericana de Derechos Humanos se ha pronunciado en contra de la discriminación por motivos de orientación sexual y a favor de la protección de los diversos modelos de familia existentes a través del caso AtalaRiffo y niñas vs Chile; en este caso el Estado chileno mediante diversas acciones, sentenció quitar la custodia y tuición ${ }^{8}$ que tenía la señora AtalaRiffo sobre sus hijas por motivos de su orientación sexual; dentro del caso, los tribunales chilenos decidieron que la preferencia sexual de la madre y el hecho de vivir con su pareja del mismo sexo eran factores o circunstancias que ponían el peligro del desarrollo de las menores y por tanto menoscababan el interés superior del menor, motivo por el cual otorgan la custodia y tuición de las menores al padre; del escrito de sentencia emitida por la Corte Interamericana en mencionado caso, de fecha 24 de febrero de 2012 (Fondo, reparación y costas), en su párrafo 78 se señala:

"78. La Corte ha establecido que el artículo 1.1 de la Convención es una norma de carácter general cuyo contenido se extiende a todas las disposiciones del tratado, y dispone la obligación de los Estados Parte de respetar y garantizar el pleno y libre ejercicio de los derechos y libertades allí reconocidos "sin discriminación alguna". Es decir, cualquiera sea el origen o la forma que asuma, todo tratamiento que pueda ser considerado discriminatorio respecto del ejercicio de cualquiera de los derechos garantizados en la Convección es per se incompatible con la misma". (Corte Interamericana de Derechos Humanos, 2012)

De este párrafo se desprende el análisis realizado por los miembros de la Corte Interamericana sobre el artículo 1.1 de la Convención, y del cual se establece que la Convención en sí prohíbe cualquier tipo de discriminación y considera que cualquier acto de discriminación que restrinja o limite los derechos establecidos por la misma (entre ellos el derecho a la familia) se consideran como tal discriminatorios.

Así mismo la Corte puntualiza en el párrafo 80 y 82 respectivamente de la sentencia mencionada con anterioridad, lo siguiente:

"80. Además, el Tribunal ha establecido que los Estados deben

${ }^{8}$ Término utilizado en Chile para referirse al derecho que es conocido en México como convivencia. 
abstenerse de realizar acciones que de cualquier manera vayan dirigidas, directa o indirectamente, a crear situaciones de discriminación de jure o de facto. Los Estados están obligados a adoptar medidas positivas para revertir o cambiar situaciones discriminatorias existentes en sus sociedades, en perjuicio de determinado grupo de personas. Esto implica el deber especial de protección que el Estado debe ejercer con respecto a actuaciones y prácticas de terceros que, bajo su tolerancia o aquiescencia, creen, mantengan o favorezcan las situaciones discriminatorias.

82. La Corte reitera que, mientras la obligación general del artículo 1.1 se refiere al deber del Estado de respetar y garantizar "sin discriminación" los derechos contenidos en la Convención Americana, el artículo 24 protege el derecho a "igual protección de la ley". Es decir, el artículo 24 de la Convención Americana prohíbe la discriminación de derecho o de hecho, no sólo en cuanto a los derechos consagrados en dicho tratado, sino en lo que respecta a todas las leyes que apruebe el Estado y su aplicación. En otras palabras, si un Estado discrimina en el respeto o garantía de un derecho convencional, incumplirá la obligación establecida en el artículo 1.1 y el derecho sustantivo en cuestión. $\mathrm{Si}$, por el contrario, la discriminación se refiere a una protección desigual de la ley interna o su aplicación, el hecho debe analizarse a la luz del artículo 24 de la Convención Americana." (Corte Interamericana de Derechos Humanos, 2012)

En este sentido la Corte Interamericana de los Derechos Humanos, se pronuncia de manera clara en cuanto a las formas de discriminación existentes que puedan efectuarse por parte de la autoridad, ya sea de hecho o de derecho, cuando una ley sustantiva (que en el caso concreto para este artículo es el Código Civil del Estado de Jalisco) realice una protección desigual, ya sea por lo que establezca o por su forma de aplicación, se está generando un acto discriminatorio y se está violentando el derecho a la igualdad de ley.

El caso de AtalaRiffo y niñas vs Chile sirve de marco referencialy comparativo, en virtud de que la discriminación que realiza el Estado chileno se da por motivos de orientación sexual y el tratamiento dado también por el Estado al considerar que la madre por ser homosexual y vivir con una pareja del mismo sexo violenta el interés superior de las menores al no ser considerada para tener derecho al desarrollo y protección de la familia, entendida desde el modelo heteroparental. El escenario planteado en este caso arroja una similitud de circunstancias y planteamientos en torno al acto discriminatorio que se ejecuta con 
la prohibición dada a parejas homosexuales para poder contraer matrimonio y adoptar de forma plena en el Estado de Jalisco.

Y en base a esta analogía, el pronunciamiento realizado por la Corte Interamericana debe de tratarse con aparejada ejecución para los artículos del Código Civil de Jalisco, obligando así al Estado de Jalisco a tomar medidas positivas para revertir la discriminación existente en la ley.

La Constitución establece la reparación de la violación de derechos humanos, lo que en este caso tendría que instituirse con dichas reformas, realizando un cambio que no discrimine, respete, proteja, y garantice el derecho a la familia para todos los gobernados, el derecho a la igualdad tanto de las personas como de la aplicación de la ley y la no discriminación, así como el otorgamiento de seguridad jurídica.

A este acto, el doctrinista Miguel Carbonell lo define como igualdad sustancial, explicándolo puntualmente de la siguiente manera:

"El estadio más reciente en el recorrido de la igualdad a través del texto de las Constituciones modernas se encuentra en el principio de igualdad sustancial, es decir, en el mandato para los poderes públicos de remover los obstáculos que impiden el logro de la igualdad en los hechos, lo que puede llegar a suponer o incluso a exigir la implementación de medidas de acción positiva o de discriminación inversa; para su aplicación conviene identificar previamente a los grupos que, dentro de cada sociedad, se encuentran en situación de mayor vulnerabilidad, respecto de los cuales se tendrán que tomar medidas de promoción y de especial protección." (Carbonell, miguelcarbonell.com, 2012).

\section{Criterios jurisprudenciales de la Suprema Corte de Justicia de la Nación}

La Suprema Corte de Justicia de la Nación, en la Tesis Aislada, con No. De Registro: 2007865, de la Primera Sala, expone lo siguiente:

"Las relaciones que entablan las parejas del mismo sexo pueden adecuarse perfectamente a los fundamentos actuales de la institución matrimonial y más ampliamente a los de la familia. Para todos los efectos relevantes, las parejas homosexuales se encuentran en situación equivalente a las parejas heterosexuales, de tal manera que es totalmente injustificada su exclusión del matrimonio. La razón por la cual las 
parejas del mismo sexo no han gozado de la misma protección que las parejas heterosexuales no es por descuido del órgano legislativo, sino por el legado de severos prejuicios que han existido tradicionalmente en su contra y por la discriminación histórica. El derecho a casarse no sólo comporta el derecho a tener acceso a los beneficios expresivos asociados al matrimonio, sino también el derecho a los beneficios materiales que las leyes adscriben a la institución."(Suprema Corte de Justicia de la Nación, 2015)

Bajo el mismo contexto, se pronuncia la Tesis Aislada con No. de registro 2006876, de la Primera Sala, la cual establece:

"Como la finalidad del matrimonio no es la procreación, no tiene razón justificada que la unión matrimonial sea heterosexual, ni que se enuncie como "entre un solo hombre y una sola mujer". Dicha enunciación resulta discriminatoria en su mera expresión. Al respecto cabe recordar que está prohibida cualquier norma discriminatoria basada en la orientación sexual de la persona. En consecuencia, ninguna norma, decisión o práctica de derecho interno, tanto por parte de autoridades estatales como de particulares, pueden disminuir o restringir los derechos de una persona a partir de su orientación sexual." (Suprema Corte de Justicia de la Nación, Suprema Corte de Justicia de la Nación , 2015)

En base a esta tesis aislada, la Suprema Corte de Justicia de la Nación señala de manera concisa el derecho que tienen las personas homosexuales a contraer matrimonio y los derechos y obligaciones inherentes al mismo; de la misma forma la SCJN se pronuncia en materia de adopción homoparental en la Tesis aislada con número de registro 161284, la cual señala:

"La protección al interés superior de los niños y las niñas consagrado en el artículo 4o. de la Constitución Política de los Estados Unidos Mexicanos, es un principio que exige su cumplimiento por parte del Estado en todos sus niveles de gobierno y ámbitos competenciales y si bien es cierto que tratándose de la institución civil de la adopción, los derechos de los menores sujetos a adopción se encuentran en posición prevalente frente al interés del adoptante o adoptantes, también lo es que ello no se traduce en que la orientación sexual de una persona o de una pareja lo degrade a considerarlo, por ese solo hecho, como nocivo para el desarrollo de un menor y, por ello, no permitirle adoptar. Cualquier argumento en esa dirección implicaría utilizar un razonamiento vedado por el artículo 10. constitucional que, específicamente, prohíbe la discriminación de las personas por razón de sus preferencias, lo que además sería contrario a la interpretación que la Suprema Corte de Justicia de la Nación ha desarrollado respecto del tipo de familia protegido por el artículo 40. constitucional y los derechos de los menores. Así pues, en el caso de la adopción, lo que exige el principio del interés superior del menor es que la legislación aplicable permita delimitar el universo de posibles adoptantes, sobre la base de que ofrezcan las condiciones necesarias para el cuidado y desarrollo del menor establecidas en la ley, para que la autoridad aplicadora evalúe y decida respecto de la que represente su mejor opción de vida, pues sostener que las familias homoparentales no satisfacen este esquema implicaría utilizar un razonamiento constitucionalmente contrario a los intereses de los menores que, en razón del derecho a una familia, deben protegerse."(Suprema Corte de Justicia de la Nación P. , 2011) 
El pronunciamiento de la SCJN es claro al establecer que la adopción homoparetal no violenta o trasgrede el principio del Interés Superior del Menor, y por el contrario manifiesta cómo este argumento trasgrede dicho principio al violentar el derecho que tienen los menores a una familia.

Dicha tesis se desprende de la interpretación dada por el máximo tribunal ante la acción de inconstitucionalidad 2/2010.

\section{Mecanismos de interpretación utilizados por la Suprema Corte de Justicia de la Nación}

En el ejercicio de resolver la acción de inconstitucionalidad promovido por el Procurador General de la República bajo el expediente 2/2010 en contra de la reforma realizada por el legislativo del Distrito Federal en materia de matrimonios y adopción por parte de personas del mismo sexo, obligó a que el pleno del máximo tribunal se pronunciara respecto a la constitucionalidad de las reformas; para ello fue necesario hacer una amplia interpretación evolutiva y análisis de los artículos $1^{\circ}$ y $4^{\circ}$ constitucional y solicitar el estudio técnico a especialistas de la Universidad Nacional Autónoma de México para pronunciar un dictamen que determinará si hay o no afectación en los menores ante la adopción homoparental.

En ese ámbito, el Alto Tribunal no sólo se pronunció ante el principio de igualdad y no discriminación en el ámbito de la diversidad sexual, sino que además determinó, entre otras cosas:

- Que las parejas formadas por personas del mismo sexo pueden llegar a constituir un núcleo familiar y que como tal es también merecedor de la protección constitucional establecida en el artículo $4^{\circ}$.

- La obligación del legislador ordinario para que, gozando de su libertad de configuración normativa, creara las figuras necesarias para proteger jurídicamente a las diversas formas de familia.

- Los gobiernos estatales que conforman la federación deberán sujetarse, en el ejercicio de sus funciones, a los mandatos de la Constitución Federal, de manera que si las leyes expedidas por las Legislaturas de los Estados resultan contrarias a los preceptos constitucionales, deben prevalecer las disposiciones de la Norma Fundamental y no las de esas leyes ordinarias. 
- Que tratándose de adopción, los derechos de los menores preponderan frente a los derechos o interés del adoptante $u$ adoptantes; sin embargo, esto no se traduce en que la orientación sexual de una persona o de una pareja, lo degradara a considerarlo como nocivo para el desarrollo de un menor, lo que podría justificar al legislador en prohibir la adopción por parte de un matrimonios homosexuales, en virtud de que se afectara el interés superior del menor, pero no es así.

La Suprema Corte de Justicia de la Nación, a lo largo de la resolución dada a la acción de inconstitucionalidad 2/2010, resuelve dentro de sus párrafos 234 y 235 , lo siguiente:

"234. En cuanto al segundo aspecto, lo que se consagra constitucionalmente es la protección de la familia -su organización y desarrollo-, dejando al legislador ordinario garantizarlo de manera tal que, precisamente, conlleve su promoción y protección por el Estado, sin que tal protección constitucional, empero, se refiera o limite a un tipo de familia ${ }^{9}$, como sería la nuclear (padre, madre e hijos) y que, de ahí, se pueda desprender que la familia se constituya exclusamente a través del matrimonio entre un hombre y una mujer y, mucho menos, que sea éste un requisito para que "proceda" la protección constitucional a la familia, como esgrime el accionante.

235. Por consiguiente, si partimos de que la Constitución no se protege exclusivamente a la familia que surge o se constituye mediante aquella institución (haciendo alusión a la familia tradicional) debido a que la protección es a la familia, entonces, dentro de un Estado democrático de derecho, en el que el respeto a la pluralidad es parte de su esencia, lo que debe entenderse protegido constitucionalmente es la familia como realidad social y, por ende, tal protección debe cubrir todas sus formas y manifestaciones en cuanto realidad existente ${ }^{10}$, alcanzando a dar cobertura a aquellas familias que se constituyan con el matrimonio; con uniones de hecho, con un padre o una madre e hijos (familia monoparental), o bien, por cualquier otra forma que denote un vínculo familia."(Suprema Corte de Justicia de la Nación, 2010)

Los ministros de la Suprema Corte de Justicia de la Nación (SCJN), en el párrafo 238, también señalan:

238. Por consiguiente, si conforme al artículo $4^{\circ}$ constitucional, el legislador ordinario, a lo que está obligado, es a proteger la organización y el desarrollo de la familia -en sus múltiples organizaciones y/o manifestaciones-, sin encontrarse sujeto a una concepción predeterminada de la figura del matrimonio, es indudable, entonces, que, en el ejercicio de esa labor, no puede dejar de lado que la familia, antes que ser un concepto jurídico, es un concepto sociológico ${ }^{11}$, pues, como lo refieren las opiniones técnicas que, en apoyo de esta Corte, elaboraron diversas facultades o escuelas de la Universidad Nacional Autónoma de México y los datos aportados en dichas opiniones, la familia, lejos de ser una creación jurídica, nace o se origina con las relaciones humanas, correspondiendo más bien a un diseño social que, por ende, se

\footnotetext{
${ }^{9}$ La letras en negro son puestas por la autora de esta tesis.

10 Ibidem 30

11 Ibidem 31
} 
presenta de forma distinta en cada cultura; así, los cambios y transformaciones sociales que se van dando a lo largo del tiempo, de manera necesaria, impactan sustancialmente en la estructura organizativa de la familia en cada época (datos que, además, se corroboran, en gran parte, con las estadísticas elaboradas en esa materia por el Instituto Nacional de Estadística y Geografía).

Bajo el marco legal establecido en el artículo $4^{\circ}$ Constitucional sobre la protección de la familia y una vez que su protección se ha interpretado por el único órgano facultado para hacerlo -Suprema Corte de Justicia de la Nación-, es un imperativo, tal y como lo marca el Alto Tribunal, que el Estado de Jalisco, por medio de su órgano legislador local, dé cumplimiento a lo estipulado por nuestra máxima Ley, la cual le obliga a proteger la organización y desarrollo de la familia en el marco de las realidades sociales que se viven en el país, y legisle brindándole la máxima protección otorgada, en este caso, incluyendo la posibilidad de la conformación de familias formadas por parejas o matrimonios homosexuales.

La opinión emitida por la Suprema Corte, resulta significativa puesto que basa dicho fundamento en las opiniones técnicas realizadas por especialistas de Universidad Nacional Autónoma de México, las cuales demuestran que no existe evidencia alguna que pueda señalar o demostrar alguna afectación hacía el menor por ser adoptado por una pareja homosexual, en este sentido, el argumento que arrojado de la afectación del interés superior del menor, se ve reducido a mera especulación, la cual no sirve de fundamento valido que pueda acreditar el hecho de la prohibición de adopción a parejas homosexuales.

De la misma forma la Suprema Corte, en el párrafo 316, de este resolutivo, establece:

"Pensar que la Constitución exige excluir del régimen legal que discipline el régimen de adopción a una categoría entera de personas definidas por su orientación sexual, implica caer en un razonamiento prohibido constitucionalmente"

Como se muestra en los dos párrafos citados anteriormente del resolutivo de recurso de inconstitucionalidad 2/2010, emitido por la Suprema Corte de Justicia de la Nación, evidencia la inexistencia de fundamentos legales o técnicos que puedan acreditar la prohibición para que adopten matrimonios homosexuales como constitucional en protección al interés superior del menor. Por el contrario, dicha prohibición resulta inconstitucional y violatorio de derechos humanos al ser a todas luces discriminatorio. 
Los estudios técnicos realizados por parte de especialistas de la UNAM y que fueron recopilados por la Suprema Corte de Justicia de la Nación, muestran que no hay elementos de investigación científica que puedan sustentar la prohibición a personas del mismo sexo a adoptar. Dentro del recurso de inconstitucionalidad 2/2010 promovido por el Procurador General de la República vs Distrito Federal, se señalan partes de los resultados dados por los especialistas de la UNAM:

"No existe ninguna base para afirmar que los hogares o familias homoparentales posean un factor anómalo que redunde directamente en una mala crianza. Quien crea lo contrario, está obligado a mostrar evidencias de ello. Ni el Procurador General de la República, ni nadie en el mundo, ha presentado tales evidencias empíricas, con estudios serios y metodológicamente bien fundados. La carga de la prueba está en quienes sostienen, prejuiciosamente, que una pareja homosexual no es igual o es peor para la salud y el bienestar de los menores que una pareja heterosexual. En realidad, quienes tienen esa creencia hacen una generalización inconsistente, a partir de algún dato particular o anecdótico y lo elevan a una característica de todo un grupo social. Estas generalizaciones inconsistentes se llaman estereotipos y éstos, a su vez, son la base cognitiva errónea de los prejuicios sociales de la intolerancia".

"No existen razones objetivas, ni científicamente fundadas, para conjeturar riesgos para los menores criados y/o adoptados por parejas homosexuales. En comparación general con las parejas heterosexuales, no hay diferencias significativas en los efectos psico-sociales para los niños (as). El interés superior de los menores consiste en su bienestar físico-mental, así como en el derecho a tener una familia o ser reintegrados en una familia cuando carecen de ella. Tanto las familias heteroparentales como las homoparentales pueden ofrecer las condiciones adecuadas para criar, cuidar y educar a niños (as) huérfanos o abandonados". (Suprema Corte de Justicia de la Nación, 2010)

Lo señalado anteriormente por especialistas, rompe con la idea de que permitir el matrimonio entre parejas homosexuales y otorgar el derecho a que adopten transgrede el derecho de los menores; por el contrario, de acuerdo con lo señalado por la SCJN y los especialistas en cuestión, esta negativa es la base errónea de los prejuicios sociales de la intolerancia, y en virtud de ello solo queda la premisa de que el ordenamiento civil discrimina claramente a la población homosexual por su orientación sexual.

Al hacer una relación entre lo que se establece por parte de la SCJN, en la resolución dada al recurso de inconstitucionalidad 2/2010, y lo que el Comité de las Naciones Unidas redacta en la Observación No. 19 señalado en apartados anteriores, la Constitución mexicana, al no establecer ni definir o restringir el concepto de familia a un modelo en particular, permite que su protección y conceptualización sea general y no limitativa; la interpretación dada por los ministros de la SCJN, establece claramente que la protección que concede nuestra 
constitución abarca a todos los tipos de familia existentes en la realidad social del País, en este caso, también protege el derecho que tienen a conformar una familia las parejas, matrimonios o convivientes homosexuales.

De la misma forma, los organismos internacionales, en este caso la ONU, a través del Comité de Derecho Humanos, recalca que cuando la legislación y la práctica de un Estado consideren a un "grupo de personas" como una familia, éste debe ser objeto de la protección prevista en el artículo 23, del Pacto Internacional de los Derecho Civiles y Políticos, así como de todos los Tratados en los que el Estado mexicano sea parte.

En México y en particular en el Estado de Jalisco, existe el imperativo, no sólo marcado en la Constitución, sino también en los Tratados Internacionales de brindar la mayor protección prevista por la Ley. Lastimosamente en diversos estados de la Nación y principalmente en Jalisco, por conducto de las omisiones realizadas por el Poder Legislativo, se violentan los derechos fundamentales y humanos enmarcados en diversas legislaciones al restringir el derecho al matrimonio y adoptar a personas homosexuales.

Al hablar de los derechos humanos y de los derechos fundamentales, en esta investigación, es necesario señalar y resaltar dos aspectos importantes:

- El primero de ellos, refiere al principio pro persona reflejo en los Derecho Humanos, este principio establecido dentro del artículo $1^{\circ}$ constitucional, deja en mandato expreso que todas las normas de Derechos Humanos se deberán de interpretar a efecto de favorecer la mayor protección para las personas, lo que en otras palabras es el llamado principio pro persona. En stricto sensu, al tratarse de Derechos Humanos y su protección constitucional, se debe de tomar en cuenta el mayor amparo y beneficio que se le pueda otorgar a las personas y la salvaguarda de sus derechos.

- En segundo lugar, tanto los Derechos Humanos, como los derechos fundamentales tienen la característica de ser universales; entendida la universalidad cómo el carácter general de la ley dejando su protección y resguardo para todas las personas sin excepción alguna.

Se remarcan estos dos aspectos -los cuales son tratados así mismo desde la doctrina como de facto en la ley- puesto que al 
hablar del derecho a formar una familia se está trasgrediendo con la omisión legislativa estos aspectos del derecho, ya que se están pasando por alto los mismos, en el caso concreto se plantea cómo no se está brindando la mayor protección del derecho aplicando el principio pro persona y, tampoco se está respetando la característica de universalidad del derecho a la familia cuando una norma sustantiva u ordinaria es limitativa a un sector de la población en particular.

\section{Sentencia del Tribunal de Distrito en materia civil del Estado de Jalisco}

En lo destacado a lo largo del presente artículo, se demuestra como existe una notable violación a los derechos fundamentales otorgados por el artículo $1^{\circ}$ y $4^{\circ}$ constitucional, trasgrediendo a su vez lo pactado en materia de derechos humanos en diversos tratados internacionales; los matrimonios entre personas del mismo sexo en el estado de Jalisco son actualmente existente a través del recurso de amparo.

Lo anterior a efecto, de que si bien las personas homosexuales no cumplen los requisitos que el Código Civil de Jalisco marca para poder casarse (ser un hombre y una mujer), se puede acceder a ellos por medio del juicio de amparo. Tal es el caso resuelto bajo sentencia, girada en torno al juicio de amparo 370/2013, en donde las ciudadanas Martha Sandoval Blanco y Zaira Viridiana de la O Gómez, en el Estado de Jalisco, se convirtieron en la primer pareja homosexual que contrajo matrimonio; esta situación dibuja un contexto social en Jalisco diferente, puesto que sí bien ya se tenían matrimonios homosexuales residiendo en el Estado -los cuales contrajeron matrimonio en el Distrito Federal tras la reforma del 2009 al ordenamiento civil de esta entidad- con este suceso se han efectuado más matrimonios bajo las mismas condiciones de Martha y Zaira;que en palabras de su abogada la Dra. María Guadalupe Ramos Ponce, actualmente existen más parejas en el Estado preparándose legalmente para poder contraer matrimonio ${ }^{12}$, sin embargo, este hecho no revierte la violación que se da ante sus

\footnotetext{
12 La Dra. Ramos Ponce realizó declaraciones en torno a la Ley de Libre convivencia del Estado de Jalisco en una entrevista dada a CNN México, en la cual detalla cómo esta ley es una opción poco viable para las parejas homosexuales que buscan obtener los derechos inherentes al matrimonio, e informa que se tienen hasta el 14 de febrero del 2014, cinco parejas en trámite de amparo para poder casarse legalmente. http://mexico.cnn.com/nacional/2014/02/14/la-libre-convivencia-unrecurso-legal-poco-atractivo-a-las-parejas-gay. Revisada al 01 de abril de 2014.
} 
derecho al no poder contraer matrimonio, por el contrario lo reafirma al concederse los amparos interpuesto y pone de manifiesto la obligación latente del legislativo para adecuar la ley en pro de la igualdad.

Miguel Carbonell, describe un aspecto de igualdad, denominada igualdad sustancial, la cual implica el cumplimiento del poder que se le ha concedido a la autoridad para que en mandato de este realice acciones que culminen en la ejecución de facto igualdad, en este contexto por ejemplo; el Juez Cuarto de Distrito en materia civil del Estado de Jalisco, facultado por el artículo 103 de la constitución mexicana para que resolver controversias sobre normas generales actos $\mathrm{u}$ omisiones que violen derechos humanos, el 27 de noviembre del 2013 dictó resolución en el cual ordenó ciertas acciones al Director del Registro Civil y Oficial del Registro Civil I de Guadalajara ${ }^{13}$ las cuales permitieron que Martha Sandoval Blanco y Zaira Viridiana de la O Gómez llevarán a cabo su matrimonio civil adquiriendo los derechos y obligaciones inherentes al mismo.

En un análisis respecto de lo que puntualizan los artículos 258, 539, fracción I, ambos del Código Civil de Jalisco y la resolución dada por el Juez Cuarto de Distrito en materia Civil del Estado de Jalisco, se realiza el siguiente cuadro comparativo, mostrando las similitudes de las redacciones de los artículos y lo ordenado por el Juez para solventar la violación de Derechos Humanos, en el párrafo sexto de la sentencia emitida.

\begin{tabular}{|c|c|c|}
\hline 39, fracción I & Artículo 258 & :ión \\
\hline $\begin{array}{l}\text { La adopción plena confiere } \\
\text { al adoptado todos los } \\
\text { efectos jurídicos, derechos } \\
y \quad \text { obligaciones que } \\
\text { corresponden a la relación } \\
\text { paternoryilial } \\
\text { consanguinea. La adopción } \\
\text { plena requiere: } \\
\text { I. Los adoptantes sean un } \\
\text { hombre y una } \\
\text { mujer }{ }^{14} \text { casados entre si y }\end{array}$ & $\begin{array}{l}\text { El matrimonio es una } \\
\text { institución de carácter } \\
\text { público e interés social, } \\
\text { por medio del cual un } \\
\text { hombre y una mujer } \\
\text { deciden compartir un } \\
\text { estado de vida para la } \\
\text { búsqueda de su realización } \\
\text { personal y la fundación de } \\
\text { una familia. }\end{array}$ & $\begin{array}{l}\text { "a) Las autoridades } \\
\text { responsables ejecutora, } \\
\text { Director del Registro Civil y } \\
\text { el Oficial del Registro Civil } \\
\text { Uno, ambos de Guadalajara, } \\
\text { Jalisco, dejen insubsistente el } \\
\text { acto reclamado consistente en } \\
\text { el oficio sin numero, de once } \\
\text { de marzo del dos mil trece y, } \\
\text { en su lugar, emitan otro en el } \\
\text { que, consideren que la lectura }\end{array}$ \\
\hline
\end{tabular}

13 Se anexa al final de la presente investigación, la sentencia dictada por el Juez Cuarto de Distrito en materia Civil como referencia de la presente investigación. ${ }^{14}$ Elremarcadoennegritasespuestoporlaautoradelapresentetesisafindeespecificarlasimilitudexistente entre los artículos 539 y 258 del Código Civil del Estado de Jalisco y el acto discriminatorio que se realiza. ${ }^{15}$ Elremarcadoennegritases puestoporlaautoradelapresentetesisafindeespecificarlasimilitudexistente entre los artículos 539 y 258 del Código Civil del Estado de Jalisco y el acto discriminatorio que se realiza. 
Como se muestra en el cuadro comparativo realizado, ambos artículos en cuestión señalan como requisito el hecho de que sean un hombre y una mujer, de lo que se desprende el resolutivo dictado por el Juez en el juicio de amparo 370/2013-X, puntualizando la obligación de la autoridad de dar lectura al artículo 258, sustituyendo "un hombre y una mujer" por "dos personas", subsanando de ésta forma la violación a derechos humanos.

Si bien existe el recurso legal, como ya se ha mencionado anteriormente, para tratar de subsanar la violación de derechos por parte de la autoridad, es necesario plantearse si con ello es suficiente para garantizar y otorgar la protección de los Derechos Humanos. De ser así, entonces ¿En dónde queda la obligación del Estado para que sus leyes sean acordes a lo enmarcado por los tratados internacionales y la constitución en materia de derechos humanos?, ¿En dónde queda la protección a la honra y a la dignidad de las personas homosexuales, la protección y el derecho a que conformen una familia, la igualdad ante la ley, si la ley sigue siendo discriminatoria?

En razón de garantizar y proteger los derechos humanos de los ciudadanos es necesario realizar las reformas pertinentes para que la ley ordinaria guarde concordancia con la máxima establecida por la constitución y los tratados internacionales.

${ }^{16}$ El remarcado en negritas se copia de forma idéntica a como ha sido escrito en la sentencia emitida por el Juez Cuarto de Distrito en materia Civil del Estado de Jalisco. 


\section{Conclusiones}

Si uno de los aspectos que conduce la forma en que un individuo proyectará su vida y sus relaciones, es su orientación sexual, es un hecho que en pleno respeto a la dignidad humana, es exigible el reconocimiento por parte del Estado a través de todas sus autoridades y sus leyes, no sólo del respeto a la preferencia sexual de un individuo hacia personas de su mismo sexo, sino también de sus uniones, bajo las modalidades que, en un momento dado se decida acoger (libre convivencia, concubinatos y el matrimonio), y su derecho a poder conformar una familia por medio del matrimonio y de la adopción.

Lo anterior precisa, puesto que a pesar de que existen los elementos jurídicos para garantizar el ejercicio de los principios a los que se ha hecho mención, en la práctica las autoridades encargadas de hacerlos valer y darles máxima eficacia han privilegiado más los intereses de tipo político, moral y religioso, bloqueando cualquier avance significativo en materia de derechos humanos, lo que representa un serio menoscabo a los derechos fundamentales de las personas, y significa un grave atentado contra los aspectos más básicos que deben sostener la estructura de un Estado moderno constitucional y democrático de derecho:

- El principio de supremacía constitucional, establecido en el artículo 133 de la Constitución Política de los Estados Unidos Mexicanos.

- El principio de fuerza normativa de la Constitución.

- Los Derechos Humanos; en el caso concreto el derecho a formar una familia, derecho a la legalidad y seguridad jurídica y derecho a la igualdad y no discriminación.

Las reformas constitucionales del 6 y 10 de junio de 2011, en materia de Derechos Humanos y el juicio de Amparo, representan una restructuración vanguardista de sistema jurídico mexicano, cuyos alcances aún están por determinarse; y por ello es indispensable destacar los siguientes puntos:

- La obligación de las autoridades, en específico de los Congresos locales, de realizar una adecuación de la ley conforme a la constitución siempre obedeciendo al principio pro persona. 
- El establecimiento de la omisión de la autoridad, en este caso el poder legislativo, como detrimento del estado de derecho y la violación a los aspectos de la dignidad humana.

Los legisladores en cumplimiento con lo que marca la constitución, deben modificar lo concerniente a esta materia haciendo valer el estado de derecho y protegiendo el derecho a formar una familia, privilegiando el derecho a la igualdad y no discriminación en el marco del principio de legalidad y seguridad jurídica.

El coartar y violentar los derechos de las personas, solo lleva a que las problemáticas sociales se agraven, en lugar de encontrar leyes que sean acordes a los derechos fundamentales ya reconocidos por la constitución y facilitar los mecanismos para otorgarles estos derechos, la imposibilidad de poder ejecutarlos orilla a estas parejas a buscar en medios alternativos, soluciones "excluyentes" o "especiales" que les permitan poder consolidar y desarrollar una familia aún fuera del marco protector de la ley ordinaria.

Bibliografía
Barbosa Delgado, F. R., Acosta Alvarado, P. A., \& Nuñez Poblete, M. (2012). El margen de apreciación en el sistema interamericano de derechos humanos: proyecciones regionales y nacionales. . México: Universidad Nacional Autónoma de México. .

Carbonell, M. (16 de mayo de 2012). miguelcarbonell.com. Recuperado el 6 de enero de 2015, de http://www.miguelcarbonell.com/ docencia/Igualdad.shtml\#

Congreso de la Unión, Cámara de diputados (11 de junio de 2003). Recuperado el 11 de diciembre de 2014, de Camara de Diputados, Congreso de la Unión: http://www.diputados.gob.mx/LeyesBiblio/ pdf/262.pdf

Constitución Política de los Estados Unidos Mexicanos (Octava ed.). (2013). México: Suprema Corte de Justicia de la Nación.

Constitución Política de los Estados Unidos Méxicanos, sus reformas y modificaciones. (2006). México, D.F.: Porrúa. 
Corte Interamericana de Derechos Humanos. (24 de febrero de 2012). Recuperado el 05 de enero de 2015, de http://www.corteidh.or.cr/index. php/16-juris/22-casos-contenciosos

Naciones unidas. (s.f.). Recuperado el 17 de diciembre de 2014, de http://www.un.org/es/ documents/udhr/\#

Organización de los Estados Americanos. (s.f.). Recuperado el 17 de diciembre de 2014, de http:// www.oas.org/dil/esp/tratados_A-41_Carta_de_ la_Organizacion_de_los_Estados_Āmericanos. $\mathrm{htm}$

Organización de los Estados Americanos. (s.f.). Recuperado el 17 de diciembre de 2014, de http:// www.oas.org/juridico/spanish/tratados/a-52.html

Organización de los Estados Americanos. (s.f.). Recuperado el 17 de diciembre de 2014, de http://www.oas.org/charter/docs_es/resolucion1_ es.htm

Suprema Corte de Justicia de la Nación, P. (agosto de 2011). Suprema Corte de Justicia de la Nación. . Recuperado el 08 de noviembre de 2015, de http://www2.scjn.gob.mx/TesisAisladas/ Paginas/DetalleTesis.aspx?IUS=3659

Suprema Corte de Justicia de la Nación, P. S. (04 de julio de 2015). Suprema Corte de Justicia de la Nación. Recuperado el 08 de noviembre de 2015, de http://sjf.scjn.gob.mx/SJFSem/ Paginas/DetalleGeneralV2.aspx?Epoca=\&Apen dice $=\&$ Expresion=MATRIMONIO\&Dominio $=$ Rub ro, Texto, Precedentes, Localizacion\&TA TJ $=\& O$ rden $=3 \&$ Clase $=$ DetalleSemanarioBusquedaBL \&Tablero $=-100 \mid 2 \&$ NumTE $=9 \& E p p=20 \&$ Desde $=-$ 100\&Hasta $=-100 \&$ Index $=0 \&$ Sema

Suprema Corte de Justicia de la Nación, P. S. (04 de julio de 2015). Suprema Corte de Justicia de la Nación. Recuperado el 08 de noviembre 
Bibliografía de 2015, de http://sjf.scjn.gob.mx/SJFSem/ Paginas/DetalleGeneralV2.aspx?Epoca $=\& A$ pen dice $=\&$ Expresion=MATRIMONIO\&Dominio $=$ Rub ro, Texto,Precedentes, Localizacion\&TA_TJ=\&O rden $=3 \&$ Clase $=$ DetalleSemanarioBusquedaBL \&Tablero $=-100 \mid 2 \&$ NumTE $=9 \& \mathrm{Ep} p=20 \&$ Desde $=-$ $100 \&$ Hasta $=-100 \&$ Index $=0 \&$ Sema 